\title{
ESCOLA, MÍDIA E COMUNICAÇÃO: SISTEMAS COMPLEXOS*
}

Regiane Regina Ribeiro**

\section{RESUMO}

Este artigo faz uma reflexão da interface educação/mídia/comunicação no cenário contemporâneo. Nesse sentido, propõe como desafio à educação reconhecer-se como sistema complexo no qual a comunicação é o elemento constitutivo e promotor dessa complexidade.

Palavras chave: Educação. Comunicação. Mídia e complexidade

A Educação hoje está inserida em um cenário de saberes separados, fragmentados e compartimentados. Essa "hiperespecialização" é uma especialização fechada em si mesma sem permitir a integração da educação em uma problemática global ou em uma concepção de conjunto. Além disso, o retalhamento das disciplinas torna impossível apreender "o que é tecido junto", isto é, o complexo, já que o sentido verdadeiro nasce das relações entre os componentes do todo.

Nesse cenário, o grande desafio da escola é entender que o desafio da globalidade é, também, um desafio da complexidade. Existe complexidade, de fato, quando os componentes (como o econômico, o político, o sociológico, o psicológico, o afetivo), que constituem um todo, são inseparáveis, existindo um tecido interdependente, interativo e interretroativo entre as partes e o todo, assim como entre o todo e as partes.

Efetivamente, a inteligência que só sabe separar fragmenta a complexidade do mundo em partes estanques, fraciona os problemas,

\footnotetext{
* Artigo recebido em 29/11/2008 e aprovado em 07/05/2009.

** Pesquisadora e professora da Universidade Estadual de Londrina, professora da Pós Graduação da Universidade Norte do Paraná (UNOPAR), doutora em Comunicação e Semiótica pela PUC-SP. E-mail: regianeribeiro@sercomtel.com.br
} 
unidimensionaliza o multidimensional, atrofia as possibilidades de compreensão e reflexão, eliminando, assim, as oportunidades de um julgamento corretivo ou de uma visão a longo prazo. De acordo com Morin,

a insuficiência para tratar nossos problemas mais graves constitui um dos mais graves problemas que enfrentamos. De modo que, quanto mais os problemas se tornam multidimensionais, maior a incapacidade de pensar a sua multidimensionalidade, quanto mais a crise progride, mais progride a incapacidade de pensar a crise, quanto mais planetário tornam-se os problemas, mais impensáveis eles se tornam. Uma inteligência incapaz de perceber o contexto e o complexo planetário fica cega, inconsciente e irresponsável (2001, p.14).

A fragmentação dos conteúdos não só trouxe a divisão do trabalho, mas também os inconvenientes do confinamento e do despedaçamento do saber, produzindo o conhecimento e a elucidação, mas também a ignorância e a cegueira.

Percebe-se que o nosso sistema de ensino, ao invés de se preocupar em resolver essa problemática, submete-se a ela. Na escola primária ensina-se a isolar os objetos e a separar as disciplinas ao invés de reuni-los e integrá-los. Obriga-se o aluno a reduzir o complexo ao simples, isto é, a separar o que está ligado, a decompor e não a recompor e a eliminar tudo que cause desordens ou contradições no processo de aprendizagem.

Em tais condições, os alunos perdem suas aptidões naturais para contextualizar os saberes e integrá-los em seus conjuntos. Ora, o conhecimento pertinente é o que contextualiza qualquer informação e, se possível, a insere no conjunto a que pertence.

Deve-se, pois, pensar o problema do ensino, considerando, por um lado, os efeitos da compartimentação dos saberes e da incapacidade de articulá-los e, por outro lado, que a aptidão para contextualizar e integrar é uma qualidade fundamental da mente humana, que precisa ser desenvolvida e não atrofiada.

Sendo assim, além do desafio da globalização e da complexidade, não se pode deixar de citar a expansão descontrolada do saber. O crescimento ininterrupto dos conhecimentos constrói um número gigantesco e discordante de linguagens. Para Morin, a única forma de solucionarse essa difícil equação é reformar o pensamento, ou seja, empregar a inteligência para responder a esses desafios e permitir a ligação de duas 
culturas dissociadas. $\mathrm{O}$ autor propõe uma reforma paradigmática que torne o aluno apto a reorganizar o pensamento (2001, p.20).

Nesse contexto, a educação deve mostrar que não há conhecimento que não esteja, em algum grau, ameaçado pelo erro e pela ilusão. Assim, toda aprendizagem comporta esse risco e o maior erro seria subestimar o problema. O conhecimento em forma de palavra, de idéia ou de teoria é o fruto de uma tradução/reconstrução por meio da linguagem e do pensamento e, por conseguinte, está sujeito ao erro. Esse conhecimento, ao mesmo tempo tradução e reconstrução, comporta a interpretação, o que introduz o risco de erro na subjetividade do conhecedor, de sua visão do mundo e de seus princípios de conhecimento. A projeção dos medos e desejos de cada um e as perturbações mentais trazidas pelas emoções multiplicam esses erros.

$\mathrm{Na}$ comunicação em sala de aula, vê-se nitidamente a presença dessa equação, pois existem muitas pessoas envolvidas e o processo de tradução/reconstrução torna-se muito mais complexo. Pode-se classificar esses erros, de acordo com Morin (op. cit, p.21), em:

Erros intelectuais: aqueles que fazem resistir à informação que não convém ou não se pode assimilar.

Erros mentais: aqueles associados ao imaginário.

Erros da razão: aqueles relacionados à utilização de uma racionalização (fechada) ao invés de uma racionalidade (aberta).

Existem, ainda, outros elementos influenciadores no processo de aquisição de conhecimento: os paradigmas, doutrinas e estereótipos que, juntos, determinam o Imprinting Cultural, termo proposto por Konrad Lorenz e adotado por Morin para dar conta da marca indelével imposta pelas primeiras experiências do animal recém-nascido. Esse imprinting marca os humanos desde o nascimento, primeiro com o selo da cultura familiar, posteriormente com o da escola, o da universidade e o da vida profissional.

Percebe-se, portanto, que o ensinar e o aprender apóiam-se numa polarização desmesurada e excludente. Esses processos baseiam-se em conceitos opostos como, por exemplo, conhecer/ignorar, inteligente/ incapaz, modelo/imitação. Esse sistema binário mantido por inclusões e exclusões é uma herança ocidentalizante da Filosofia que reforça o 
pensamento dicotômico e pertence ao que se chama, tradicionalmente, de lógica binária.

Entende-se que a dicotomia é um dos paradigmas que apresentam uma valoração simplificadora que exclui o raciocínio e produz uma reação de conforto rápido e cômodo em um mundo de complexidade crescente. Assim, determinar um aprendizado como certo ou errado parece funcionar como barreira para a dúvida e para a necessidade de pensar.

Morin escreve que, no reino cosmofísico ou astrofísico ou químico-físico, as dicotomias são uma mentira. Por isso, a ciência clássica terminou reconstruindo, nesse mesmo âmbito, as dicotomias que existem no mundo ideológico.

Baggio apresenta essa dicotomia como

características do pensamento tradicional, com forte influencia do pensamento grego que foi mantido no decorrer da história e que ainda se faz presente na sociedade contemporânea, é a criação de linguagem dicotômica pela qual o humano é percebido, tratado, educado. Esse paradigma antropológico opõe natureza à cultura, fragmenta o humano em razão-emoção, sujeito-objeto, academicismo-objetividade, corpo-alma, matéria-espírito, masculino-feminino, hemisférios cerebrais direitoesquerdo e o conhecimento a partir de identidade e da não identidade (1999, p.26).

E, ainda o mesmo autor (op.cit., p.4), aponta implicações para quem não consegue ver além da dicotomia:

O nefasto desse tipo de compreensão está na distinção, por vezes oposição, lançada sob aspectos indissociáveis, assim como a limitação, que toda a polarização traz, por ignorar tantos outros elementos intermediários ou distintos que compõem a vida.

Também a vida diária, conseqüentemente, é contaminada pela lógica binária criando problemas de oposição tais como: pai/filho, homem/mulher, criança/adulto, etc. Toda essa série de dicotomias está relacionada à linearidade verbal (início, meio e fim). A linearidade deu cunho físico concreto sob a forma de dígitos àquilo que o mundo do conhecimento já organizava de modo abstrato, ou seja, dígitos seqüenciais que devem ser lidos um após o outro, obrigatoriamente, o que solidifica 
essa noção. Cada membro, após ser lido é, simplesmente, abandonado em função do subseqüente.

Morin (1997, p.25) afirma que

o regresso ao começo não é um círculo vicioso se a viagem, como hoje a palavra trip indica, significa experiência, donde se volta mudado. Então, talvez, tenhamos podido aprender a aprender aprendendo. Então, o círculo terá podido transformar-se numa espiral onde o regresso ao começo é, precisamente, aquilo que se afasta do começo.

Reforça-se, portanto, a idéia de que a linearidade favorece a noção de conhecimento acumulado e quantitativo ao invés de oferecer possibilidades de relações complexas. Para Morin (1990, p.08), a palavra complexidade lembra problema, e não solução. Não é utilizada para designar idéias simples, e tampouco se reduz a uma única linha ou vertente do pensamento. Pensamento complexo é aquele capaz de considerar todas as influências recebidas: internas e externas. O pensamento complexo não pode ser linear. A complexidade integra os modos simplificadores do pensar e nega os resultados mutiladores, unidimensionais e reducionistas.

A dificuldade do pensamento complexo é justamente enfrentar a confusão, a incerteza, a contradição e, ao mesmo tempo, conviver com a solidariedade dos fenômenos existentes em si mesmos. Tal qual o humano, que é um ser complexo, pois concentra fenômenos distintos que influenciam suas ações e provocam transformações, assim também é o conhecimento.

De acordo com Demo, o conceito de Complexidade remete ao conceito já comum de caos estruturado; para ele, um fato complexo

é caótico no sentido de que seu ser apresenta-se dotado de propriedades não lineares ou de dinâmica também ambígua/ambivalente. É estruturado porque, na maior desordem, sempre é possível divisar alguma ordem" (2002, p.13)

Ainda segundo o autor, a complexidade apresenta características que, entendidas, facilitam a compreensão do conceito e a sua utilização; são elas:

a) Dinâmica: não pode ser complexo o que não for campo de forças contrárias, em que eventual estabilidade é sempre re-arranjo provisório. 
A dinamicidade não deve executar movimentos permanentes, na mesma direção, como as estruturas sistêmicas, que acentuam as mudanças dentro do sistema, fechando-se em si mesmas, perdendo de vista a mudança.

Assim, segundo Demo,

a ciência, para persistir na sociedade, precisa constituir paradigma, até porque é condição social de validade. Surgem escolas, representantes relevantes de teorias; práticas, instituições específicas físicas e virtuais (institutos, editoras, programas, sites). Assomam-se também seguidores, discípulos e todos os que acabam vivendo à sombra do paradigma, já tornado, para essa gente, 'teoria oficial'. Esse lado da estrutura entretanto, não foge da invasão da dinâmica, também própria do conhecimento científico: quanto mais paradigmática a escola científica, menos científica tenderá a ser, ou seja, quanto mais alguém se imagina 'valer' em sociedade, menos é capaz de manter essa validade, porque começa a fazer algo que agride a unidade de contrários: perdendo a visão crítica e autocrítica, abandona o argumento e refugia-se na auto defesa. (2002, p.14)

Ou seja, todo paradigma científico, enquanto é institucionalmente defendido, também é institucionalmente corroído pela ação implacável da dinâmica do tempo. A mediocridade tende a tomar conta da escola, já que toda defesa tende a ser medíocre; ao invés de revelar tanto mais o desafio da inovação, evita-o por medo da mudança. $O$ fechamento institucional, natural na sociedade, não resiste à corrosão do tempo, o que também não é menos natural.

É preciso observar que a dinâmica indica processo que, a partir de componentes formalizáveis e controláveis, detém outros estritamente incontroláveis e não formalizáveis. Dinâmica controlável não é dinâmica propriamente, pois se restringe a rotas previsíveis. Rota propriamente criativa é aquela que avança no imprevisível; a dinâmica implica o desconhecido necessária e intrinsecamente.

b) Não-linearidade: a não-linearidade implica muito mais que emaranhados, labirintos e complicações onde podem-se ver processos que se complicam, mas não se complexificam. Multiplicidade de coisas não faz complexidade necessariamente, até porque o complexo pode provir do simples e vice-versa. É preciso ultrapassar a noção de simples organização das partes para uma relação do todo e as partes, feita ao mesmo tempo de relativa autonomia e profunda dependência. A não-linearidade 
implica equilíbrio em desequilíbrio, já que a segurança de algo fechado coincide com a sua morte. Para continuar existindo, é mister mudar, não apenas mudar linearmente, de modo previsível, tranqüilo, controlável, mas de modo criativo, surpreendente e arriscado.

No todo complexo convivem estruturas e dinâmicas desencontradas, como é, por exemplo, o processo de amadurecimento e envelhecimento, de funcionamento e de fadiga, de vigência e de passagem. Não é possível resolver essa equação, por que não é uma equação linear e isso fortaleceu a tendência de assumir a noção de resolver problemas com a proposta de livrar-se deles. Segue daí que o ideal seria a situação sem problemas, marcada pela rotina tranqüila de todos os dias, um após o outro. Observando-se bem, não há problema maior do que não ter nenhum: só realidades mortas, se existissem, seriam assim. Resolver problemas significaria, primeiro, não cultivar aqueles inúteis, insolúveis, irrelevantes; e, segundo, fomentar aqueles criativos, que abrem potencialidades de horizontes novos, energizam e motivam, levando sempre a apreender.

É preciso estabelecer essa perspectiva no ambiente escolar, modificando os discursos e as práticas lineares que reduzem a aprendizagem a um saber extenso e cumulativo que impede a percepção do complexo. O preço de uma autonomia na comunicação escolar é pensar complexamente.

c) Capacidade reconstrutiva: a natureza não é vista somente como uma usina sistêmica replicadora, mas como um sistema dinâmico caótico e criativo, capaz de efetivar e, sobretudo, de criar potencialidades irreversíveis. Marcada pelo efeito do tempo, tais estruturas dissipativas conseguem produzir processos que, aparentemente, ultrapassam os pontos de partida e sinalizam dimensões inovadoras. Tudo é uma questão de codificação e torna-se fundamental perceber seus limites. Assim, seu significado é sempre reconstrutivo. Se se colocarem vinte pessoas em torno de uma mesa e se contar à primeira uma pequena história, que a contará para a segunda e, assim, sucessivamente, constatar-se-á que o relato chega à última pessoa de modo deturpado, porque foi naturalmente reconstruído nessa trajetória. Não se consegue reconstruir a história, como se fosse texto xerocado, porque o potencial cultural de cada pessoa interfere alterando e modificando a mensagem inicial. 
Todavia, quando se grava sucessivamente em vinte computadores o mesmo arquivo, tem-se o mesmo conteúdo em todos eles. Por isso podese refletir sobre a idéia de que os computadores, como os temos hoje, são máquinas sofisticadas, complicadas, mas não propriamente complexas. Nem mesmo quando se torna apto a reproduzir textos pela técnica do hipertexto, alcança qualquer dimensão não linear: todo hiperlink puxa o hipertexto a que está linearmente ligado, nada mais. Essa técnica enriquece a produção de textos, mas não passa de técnica replicadora. Não é capaz, sozinha, de recriar, interpretar, construir texto. Essa atividade criativa permanece nas mãos do usuário, o que tem levado a se reconhecer que não existe propriamente software educativo: a capacidade educativa do software provém do educador, não da tecnologia em si, que constitui artefato muito complicado, mas estritamente linear.

Há ainda uma forte polêmica sobre o processo criativo. De partida, é comum imaginar que "criar" é como retirar do nada. Mas, na natureza, nenhum processo dinâmico se retira do nada, tudo é reconstrutivo. Essa reconstrução da complexidade aponta para outras dimensões fundamentais como sentido de autonomia e aprendizagem. Tanto o processo evolutivo quanto o histórico insinuam fortemente que não se trata de mero crescimento cumulativo, mas qualitativamente diferenciado. As espécies não se complicam apenas, se complexificam. A natureza, a não ser em seus códigos formais, jamais se repete. É, nisso, tipicamente produtiva. O ritmo temporal varia enormemente, como afirma De Landa, ao interpretar a dinâmica social dos últimos mil anos, não pela via hermenêutica comum, mas pela geologia, para mostrar que em termos de dinâmica não linear, uma nada deve a outra:

a dinâmica reconstrutiva pode ser vislumbrada não apenas em fenômenos que nos aprecem frontalmente históricos, como seriam as sociedades humanas, mas igualmente em fenômenos geológicos e naturais: a pedra não se move na dimensão humana do tempo, já que 70 anos representam, para esta, vida toda; pareceria esdrúxulo falar de dialética da pedra; no entanto, em sua dimensão própria do tempo - milhões e milhões de anos - , move-se tanto quanto a flor que desabrocha e fenece em alguns dias. (1997, p.86)

Assim, pode-se entender que, nos sistemas complexos, a parte simples é, como regra, descartável. A parte complexa é intrínseca. $\mathrm{Na}$ complexidade, as partes formam hierarquia convergente que estabelece 
campo de força entre elas, de tal sorte que flui uma dinâmica produtiva, mas não cumulativa e contígüa. Segundo Morin, existe uma constituição hologramática para indicar que o todo está na parte e a parte no todo, ou seja: em cada parte, está o sentido do todo, mas não o todo propriamente, porque, se assim fosse, não se poderia dizer que o todo é maior que a soma das partes. Na verdade, essa expressão é incorreta: nenhum todo complexo é soma. É, sobretudo, trama, rizoma, teia.

A autonomia do complexo advém da tessitura sistêmica, de um lado, mas realiza-se na dinâmica também não-sistêmica, de outro, porque sua criatividade provém de sistema em constante amadurecimento e falência consigo mesmo. Metaforicamente, pode-se apelar para o alcance de um ideal, que ao ser alcançado, deixa de ser o ideal. O ideal de um ideal é não se realizar, assim como a utopia: um lugar que marca a falta de lugar. Utopia realizada deixa de ser utopia. Todavia, sem ela, contenta-se com o que se tem.

A complexidade produz a sua autonomia na incompletude, porque, a rigor, somente realidades incompletas podem ser autônomas. Autônomo não é o que pode separar-se, isolar-se, incomunicar-se, mas o que precisa de complemento, de atualização para manter-se em horizonte próprio. Só é possível ser autônomo com referência aos outros, nunca sozinho. A autonomia constitui dependência negociada, pois sujeito não é o que exclui o outro, mas o que convive sem perder-se e sem apenas dominar.

Então, é evidente que a linearidade é prejudicial para a construção de qualquer linguagem e conhecimento. A educação tradicional apresenta questões que não fogem da leitura seqüencial e não obrigam à releitura, não afastando, conseqüentemente, o emissor e o receptor da dicotomia. De algum modo, pode-se dizer que os sistemas de signos, em geral, não cabem nas concepções dicotômicas que os filósofos da tradição ocidental criaram: mente/matéria, corpo/alma, sujeito/objeto, significante/significado e várias outras.

d) Processo dialético evolutivo: o cérebro humano é o principal exemplo desse processo já que levou milhões de anos em formação para atingir o patamar atual e possui visivelmente habilidades reconstrutivas e seletivas que ultrapassam, de longe, propriedades lógicas reversíveis. Assim também é a capacidade de aprender. Quando se imagina que processos complexos podem ser aprendidos, insinua-se apenas que esses processos 
devem incluir criatividade autêntica, no sentido de produzir modos de ser que são sempre vir a ser, de reconstrução e não de criação.

e) Irreversibilidade: refere-se à inserção temporal na qual, com o passar do tempo, nada se repete, por mais que possa parecer. Refere-se ainda, ao caráter evolutivo histórico da natureza. Assim como o ser humano nasce, vive, cresce e morre, a natureza também não volta a sua forma original. A passagem dinâmica acarreta inovação intrínseca em maior ou menor grau, de tal forma que os produtos sempre acabam tornando-se processos. Nada está propriamente pronto, porque a incompletude é o que garante o deu caráter processual.

Todo fenômeno complexo possui individualidade. Se observarmos o cérebro humano, de um lado, todos são iguais, fisiologicamente falando; de outro, cada um é profundamente diferente do outro, porque a evolução histórica implica experiências variadas no espaço e no tempo, ativação maior ou menor de certas rotas neuronais, seletividades preferenciais de motivação. Assim também acontece na cultura, todas possuem traços comuns, mas cada uma é marcada por criatividade própria. Quando ocorre a truculência de uma cultura impor-se a outras culturas, a irreversibilidade individual aparece no fenômeno inevitável da aculturação, por meio da qual a cultura violentada reage a seu modo, mesmo quando descaracterizada.

f) Ambiguidade/Ambivalência: a ambigüidade refere-se à estrutura, no sentido da composição também desencontrada de seus componentes, típica da unidade de contrários. Estruturas ambíguas não facultam sobreposições rígidas, replicadoras de si mesmas, porque são caóticas intrinsecamente. Embora em todo caos seja possível identificar estruturas, porque existir é também proceder de alguma forma, predomina a abertura para novos desafios não contidos no que está dado, até porque nunca é possível estabelecer o que já está dado e o que se poderia dar.

A ambivalência refere-se à processualidade dos fenômenos complexos, mais facilmente visível porque vinculada a seus modos de vir a ser. Algo é ambivalente quando sua dinâmica é constituída de valores contrários, estabelecendo entre eles campos contrários de força. Assim essa característica é melhor visualizada em fenômenos de tessitura mais qualitativa, como participação, envolvimento, felicidade, conhecimento, aprendizagem. Como argumenta Bova, 
enquanto a sociedade, de uma parte, pressiona para a reprodução medíocre e conservadora do sistema social, persiste nela força irresistível que é o conhecimento. Conhecimento só 'conhece' se for questionador e inovador. Por isso vale dizer que argumentar é questionar. (1990, p. 244)

E afirma, ainda que

as instituições humanas são inerentemente conservadoras. Lei, religião, escolas, costumes sociais, todas as instituições humanas estão enraizadas na necessidade de prover bases firmes e estáveis para as interações sociais (ib)

$\mathrm{Na}$ história da espécie humana, a força inovadora sempre foi, acima de tudo, fruto do conhecimento crítico: a parte da espécie que sabe construir conhecimento próprio desenvolve tecnologias de mudança irrefreável, civiliza-se e impõe-se a outras sociedades.

Portanto, conhecimento é intrinsecamente constituído de certezas ambivalentes, ou de ambivalências certas, razão pela qual se mantém inovador. Nada seria mais conservador no conhecimento do que a produção de certezas. Todavia, a desconstrução e a possibilidade de reconstrução é a alma do conhecimento inovador.

Já foi dito que aprende-se do que já se havia aprendido, conhece-se com base no conhecido, lançando-se mão do nosso patrimônio cultural disponível. Porém, mesmo que se quisesse apenas transmitir conhecimento, isso seria impraticável diante de dois horizontes entrelaçados: é inviável biologicamente, porque o trajeto evolucionário dotou os seres humanos de cérebro tipicamente reconstrutivo, e é inviável culturalmente, pois história e cultura oferecem o contexto intrínsecamente criativo da linguagem e da interpretação.

Mesmo assim, a tendência padronizante da sociedade leva a captar a realidade de forma estática. Não se capta propriamente o movimento, sobretudo não linear, mas o lado linear das dinâmicas, sempre atrás de regularidades e até mesmo de "leis" da realidade. É assim que se reage, por exemplo, ao desconhecido: primeiro se busca o que nele havia de conhecido, familiar; segundo, destaca-se o que nele se repete, porque se domina melhor o que se apresenta de modo uniforme, homogêneo. Instintivamente, diante da dinâmica estonteante, o ser humano sente-se menos perdido quando vislumbra nela pontos recorrentes, séries recursi- 
vas, modos de ser. Não é sem alguma razão que o positivismo, sobretudo o empirista, insiste no "reteste" como critério metodológico fundamental. Por trás dessa exigência aparentemente lógica está a expectativa estática da realidade reversível, sobretudo confiável. Implica fatal pressuposto epistemológico que tem como resultado a "ditadura do método", tal qual, segundo Morin (2001), ao invés de o método procurar captar a realidade, seleciona nela o que pode captar e declara real apenas o que capta.

Isso se dá porque cenários instáveis, caóticos e móveis provocam mal-estar. Resta a impressão de que o cérebro está melhor evoluído para desenhar cenários de ordenamento da realidade. $\mathrm{O}$ que se repete é mais interessante para a ciência do que aquilo que se cria.

Entretanto, a atividade padronizadora do cérebro não poderia ocultar a sua outra face: após desenhar cenários recorrentes, é capaz de penetrar além das aparências, dando a entender que a captação de regularidades não implica necessariamente reduzir a realidade a recorrências lineares. Não é menos impressionante a potencialidade de intervenção alternativa do conhecimento que introduz inovações em tudo que se encontra: na natureza, na sociedade e em si mesmo. Conhecer, como já foi dito, é, profundamente, confrontar-se, revoltar-se, não aceitar as coisas como estão, pretender para além do razoável usar a razão para sobrepor seus próprios limites. O senso padronizador serviria apenas como porta de entrada. Longe de ser atividade reprodutiva, implica confronto com a realidade no sentido reconstrutivo ostensivo. É importante ver mais do que a aparência, surpreender curvas inesperadas, agir como sujeito que reconstrói a realidade, não como objeto inerente.

É esse tipo de comportamento que a escola deve assumir, ao invés de pedir aos alunos que "fichem livros", tomem nota para memorizar ou façam provas reprodutivas. É dever da escola conduzir o aluno a um processo de desconstrução e construção da realidade.

De acordo com Hofstadter (2001) são capacidades essenciais para a inteligência:

- responder a situações de maneira muito flexível;

- tirar vantagens de circunstâncias fortuitas;

- dar sentido a mensagens ambíguas ou contraditórias;

- reconhecer a importância relativa de elementos de uma situação;

- encontrar similaridade entre situações, apesar das diferenças; 
- encontrar diferenças entre situações, apesar das que possam uni-las;

- sintetizar novos conceitos, tomando conceitos anteriores e reordenando-os de maneira nova;

- formular idéias que constituam novidades.

A inteligência reside, portanto, em dar conta de situações complexas, surpreendentes, aparentemente inesperadas e insolúveis. É saber andar por linhas tortas, é saber aprimorar a criatividade dos caminhos tortuosos, porque somente eles são criativos, não lineares e abertos. A escola não deve privilegiar a tática analítica, que vai do complexo ao simples, supondo que, no nível mais simples, se possa encontrar a essência da realidade e sua própria explicação. Nessa rota, inteligência é essencialmente exercício lógico. Saber pensar não é somente ver a lógica das coisas, formular raciocínios formais concretos, mas principalmente identificar lógicas onde aparentemente ela não existiria, pensar flexivelmente para dar conta da realidade flexível, decifrar o que é ambíguo e contraditório, ordenar a importância de elementos embaralhados numa situação, encontrar similaridades ou diferenças onde parece não haver, reconstruir o conhecimento anterior e formular perspectivas inovadoras.

Nessa perspectiva, a ação comunicativa no processo de aprendizagem não pode ter começo, meio e fim, porque está culturalmente contextualizada. Ao buscar definir conceitos, usam-se conceitos não definidos. Ao se encerrar uma discussão, deve-se restringir o final apenas ao evento focalizado sem descartar a necessidade de sempre argumentar mais e melhor. Nada começa de um ponto zero e evidente do qual poderia emanar a mesma evidência para todos os passos sucessivos, porque não se tem como chegar a um porto seguro, onde tudo já estaria explicado.

\section{ABSTRACT}

This article is a reflection on the education/media/communication interface in the contemporary scenario. Accordingly it proposes a challenge to education to recognize itself as a complex system in which communication is the constitutive element and promoter of this complexity.

Keywords: Education. Communication. Media and complexity. 


\section{REFERÊNCIAS}

BAGGIO, A.; ORTH, M. R. B. Crise paradigmática: Complexidade na orientação educacional. 1. ed. Erechim: EDIFAPES, 2001.

BOVA, B. Immortality: how science is extending your life span, and changing the world. New York: Avon Books, 1988.

DE LANDA, M. A thousand years of nonlinear history. New York: Simon \& Schuster. 1999.

DEMO, P. Metodologia científica em ciências sociais. São Paulo: Atlas, 1981.

HOFSTADTER, D. R. Godel, Escher, Bach: um entrelaçamento de gênios brilhantes. Brasília: UNB, 2001.

MORIN, E. O método 4; as idéias. Porto Alegre: Sulina, 2001.

. A cabeça bem feita: repensar a reforma, reformar o pensamento. Rio de Janeiro: Bertrand Brasil, 2001. 2000 .

. Os sete saberes necessários à educação do futuro. São Paulo: Cortez,

; MOIGNE, Jean-Louis. A inteligência da complexidade. São Paulo: Peirópolis, 2000. 